\title{
Clozapine induced pulmonary embolism in a patient with no pre-existing risk factors: A case report
}

\author{
Jing Yi Kwan ${ }^{1}$ and Maha Noor ${ }^{1}$ \\ ${ }^{1}$ Bradford District Care NHS Foundation Trust
}

January 27,2022

\begin{abstract}
We report the case of a 51-year-old Caucasian woman who developed a pulmonary embolism in the absence of any pre-existing risk factors for VTE, three weeks following clozapine initiation for treatment resistant paranoid schizophrenia. She was initially misdiagnosed and treated for suspected COVID-19 infection.
\end{abstract}

\section{Hosted file}

Clozapine induced $\mathrm{PE}$ in a patient with no risk factors - Clinical Case Reports.docx available at https://authorea.com/users/457558/articles/554301-clozapine-induced-pulmonaryembolism-in-a-patient-with-no-pre-existing-risk-factors-a-case-report

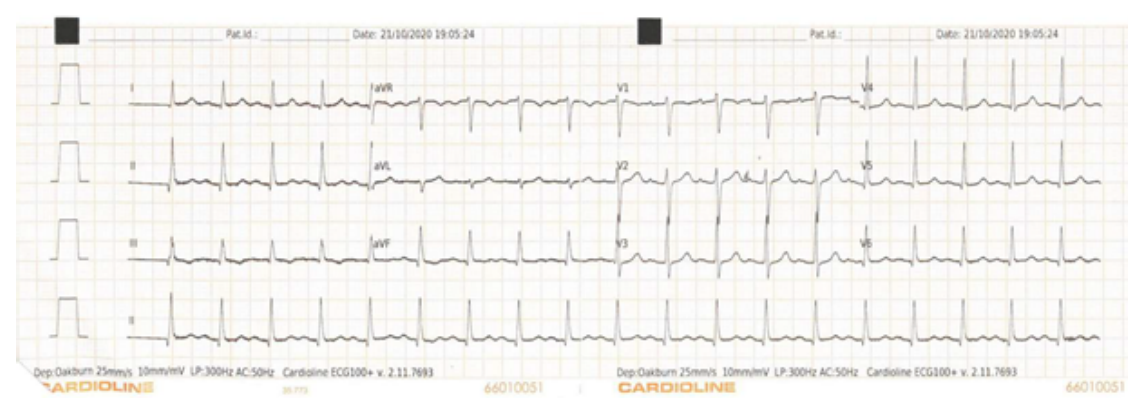



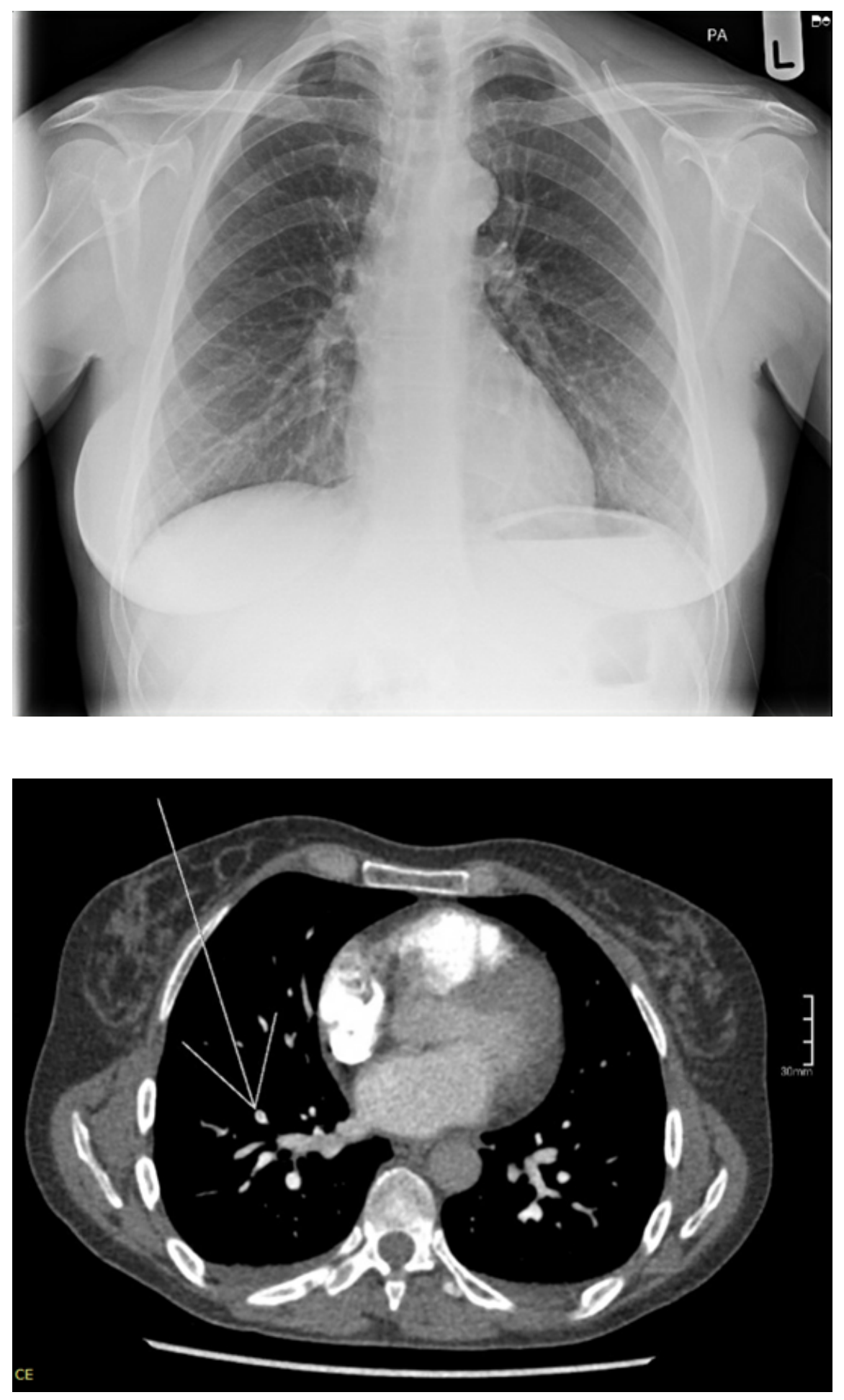